\title{
CORRELAC̄̃̃O ENTRE A BIOMETRIA TESTICULAR, A IDADE E AS CARACTERÍSTICAS REPRODUTIVAS DE TOUROS DA RAÇA NELORE
}

\author{
Marcio Saporski Segui ${ }^{1}$, Thais Angela Turra ${ }^{1}$, Emanuel Faleiros ${ }^{1}$, \\ Romildo Romualdo Weiss ${ }^{2}$, Luiz Ernandes Kozicki ${ }^{1}$, Ivo Walter Santos ${ }^{2}$ \\ 1 Pontifícia Universidade Católica do Paraná - kozicki.I@pucpr.br \\ 2 Universidade Federal do Paraná
}

\begin{abstract}
RESUMO: O objetivo da pesquisa foi o de correlacionar a dinâmica de crescimento da biometria testicular com as características espermáticas em animais em fase de crescimento e destinados à reprodução. Foram utilizados 20 animais da raça Nelore entre 10 e 24 meses de idade, criados sob condições extensivas de pastoreio e com suplementação mineral. Constituíram-se dois grupos (G), sendo o $G 1(n=10)$ formado por animais com a idade variando de 10 a 18 meses e o $G 2(n=10)$ por animais com idade entre 18,1 e 24 meses ao início do experimento. Por um período de dez meses, em três distintos momentos experimentais, com intervalos de cinco meses entre eles, nos animais de ambos os grupos, realizou-se a aferição do peso corporal, mensurações da circunferência escrotal (CE), além de avaliação do vigor, motilidade e concentração espermáticas. Houve influência da idade e do desenvolvimento corporal sobre as características reprodutivas estudadas. Ao se comparar o crescimento testicular, verificou-se que os animais do G1, tiveram maior proporção de crescimento biométrico testicular $(P<0,001)$ que os animais do $G 2$; a concentração espermática foi constantemente maior nos animais do $G 2$, nos três momentos estudados $(P<0,001)$, porém os grupos não diferiram quanto ao vigor e a motilidade espermática em todo o período experimental.
\end{abstract}

Palavras-chave: biometria testicular; circunferência escrotal; espermograma; Nelore; vigor motilidade concentração espermáticas

\section{CORRELATION BETWEEN TESTICULAR BIOMETRY, AGE AND THE REPRODUCTIVE CHARACTERISTICS OF NELLORE BULLS}

\begin{abstract}
The aim of the present experiment was to establish an interrelationship between the testicular and spermatic biometry of young bulls for breeding. Twenty bulls of the Nelore bred, between 10 and 24 months were used. The animals a monthly measurement of the perimetral scrotum and vigor, motility and sperm concentration were submitted. During the experimental period bulls lived under pasturage conditions with mineral supplement. The experimental bulls were divided in two groups: G1 formed by 10 animals, aging from 10 to 18 months, and G2, also with 10 animals but aging 18.1 to 24 months. The evaluated reproductive parameters allowed conclude that both age and body development may exert influence on the studied reproductive characteristics. By comparison of both groups in regard to the age, it has been found that the animals from the G1 disclosed a superior testicular biometric development $(P<0.001)$ than the bulls from the $G 2$, the sperm concentration increased in $G 2$, as they age increased $(P<0.001)$. The vigor and the motility sperm did not affected by the age in the period.
\end{abstract}

Key Words: Nellore bulls; scrotal circumference; testicular biometry; spermatic vigor motility concentration 


\section{INTRODUÇÃO}

A bovinocultura de corte brasileira, com o maior rebanho comercial do planeta, tornou-se forte concorrente de outros países produtores de carne, pois passa por significativas transformações, no sentido da busca de meios para elevar a produtividade e a eficiência econômica e produtiva do setor, tornando-a uma atividade atraente e competitiva (Silveira et al., 2004).

As características associadas à reprodução podem ser consideradas como as de maior importância na economia pecuária, e recebem atenção especial dos criadores (Dias et al., 2008). Ao se avaliar um reprodutor, parâmetros da biometria testicular, puberdade, libido, capacidade de serviço $e$ as qualidades física e morfológica do sêmen, devem ser levadas muito em consideração. Além dos parâmetros já mencionados e no intuito de maximizar a precisão na escolha de reprodutores, Unanian et al. (2000) ressaltam a necessidade de se efetuar, exames específicos do volume bem como a forma dos testículos e da bolsa escrotal.

Dentre os exames clinicoreprodutivos das gônadas masculinas, Pacheco et al. (2007), salientam as dimensões do perímetro escrotal (PE), que são medidas de fácil obtenção, e de alta repetibilidade e herdabilidade segundo Sesana et al. (2007), sendo igualmente consideradas como características indicativas de precocidade sexual e fertilidade por Bergmann et al. (1998). Silva et al. (2002) confirmam a existência de uma correlação positiva entre o peso corporal do animal e a fertilidade, dentre outras características de mérito econômico.

Para animais jovens destinados à reprodução, a idade à puberdade tem sido considerada como aquela em que se detectam os primeiros espermatozóides no ejaculado (Unanian e Silva,
1997), constituindo-se em um período, onde se verifica acelerado desenvolvimento reprodutivo (Freneau et al., 2006). No caso específico de bovinos de corte, há grande interesse em se estimar o desenvolvimento testicular em animais antes dos 24 meses, por ser este o período, que antecede ou que coincide com a sua utilização na atividade reprodutiva de fazendas (Valentim et al., 2002; Sesana et al., 2007).

O objetivo do presente experimento foi o de correlacionar a biometria testicular com o crescimento testicular, vigor, motilidade e concentração espermática, de touros jovens da raça Nelore destinados à reprodução, utilizando animais da faixa etária de 10 a 18 meses e de 18 a 24 meses.

\section{MATERIAL E MÉTODOS}

O experimento foi executado na Cabanha Rosazul, situada no município de Palmeira (PR) $\left(25^{\circ} 25^{\prime} 44^{\prime \prime} \mathrm{S}\right.$, $50^{\circ} 0^{\prime} 21^{\prime \prime} \mathrm{W}$ ), entre os meses de setembro de 2007 e julho de 2008. O clima dessa região é subtropical, úmido mesotérmico, sendo a média anual da temperatura de $20^{\circ} \mathrm{C}$. Foram avaliados 20 animais da raça Nelore, com a faixa etária entre 10 e 24 meses e com escore corporal 3,0 (escala de 1-5), no início do experimento. Formaram-se dois grupos $(G)$, sendo o $G 1$ constituído de dez animais com idade entre 10 e 18 meses e o G2 $(n=10)$ entre 18,1 e 24 meses. Os animais eram mantidos em pastagens cultivadas e com suplementação mineral em cochos.

Por um período de dez meses, em três distintos momentos experimentais (setembro de 2007, fevereiro de 2008 e julho de 2008), com intervalos de cinco meses entre eles, nos animais de ambos os Grupos, realizaram-se a aferição do peso corporal, mensurações 
Tabela 1 - Valores médios $( \pm s)$ da Idade inicial, circunferência escrotal (CE) em três momentos, com intervalos de 5 meses e diferença entre momentos, em bovinos da raça Nelore $(n=20)$. 2007/2008

\begin{tabular}{lccccc}
\hline \multirow{2}{*}{ Grupo } & Idade & \multicolumn{3}{c}{ Circunferência Escrotal $(\mathrm{cm})$} & Diferença entre M1 e \\
\cline { 3 - 5 } & (meses) & $M 1$ & $M 2$ & $M 3$ & M3 (cm) \\
\hline G1 & $15,5 \pm 1,0$ & $20,3 \pm 1,5^{\mathrm{a}}$ & $30,3 \pm 3,1^{\mathrm{b}, \mathrm{c}}$ & $33,4 \pm 2,7^{\mathrm{c}}$ & $13,0 \pm 1,7^{\mathrm{F}}$ \\
G2 & $24,6 \pm 1,3$ & $26,1 \pm 3,1^{\mathrm{a}}$ & $32,8 \pm 2,6^{\mathrm{b}}$ & $34,72,4^{\mathrm{c}}$ & $8,5 \pm 2,4^{\mathrm{G}}$
\end{tabular}

G1 = idade entre 10-18 meses; G2= idade entre 18,1 e 24 meses

$\mathrm{M} 1=\mathrm{set} / 2007 \mathrm{M} 2=\mathrm{fev} / 2008 \mathrm{M} 3=\mathrm{jul} / 2008$

Diferentes letras minúsculas na mesma linha e maiúsculas na mesma coluna indicam valores diferentes $(P<0,001)$.

da circunferência escrotal (CE), além de avaliação do vigor, motilidade e concentração espermática.

A mensuração da circunferência escrotal (CE) realizada com o auxílio de fita métrica foi feita no sentido transversal de ambas as gônadas (parte do maior diâmetro), aferido com fita métrica $(\mathrm{cm})$. O sêmen era colhido por eletroejaculação, avaliando-se o vigor, a motilidade e a concentração espermáticas. Os animais eram pesados após a colheita de sêmen.

As análises estatísticas foram executadas utilizando-se o programa do SAS (1990). Foram calculadas as médias simples das características avaliadas e seus respectivos desviospadrão, estimadas as variações com o teste $\mathrm{T}$ e o teste $\mathrm{F}$ de Snedecor-Fischer e o seu grau de significância.

\section{RESULTADOS}

Os dados obtidos encontram-se expostos nas tabelas de 1,2 e 3 . A circunferência escrotal dentro do grupo em M1 (set/2007) e M2 (fev/2008), diferiu $(P<0,001)$ tanto no $G 1$ como no G2, não porem entre os grupos dentro do mesmo momento (Tabela 1). Ao se verificar a variação das três mensurações (set/2007, fev/2008 e jul/2008), para ambos os Grupos, observou-se diferença $(P<0,001)$ no crescimento gonadal. Entretanto, o crescimento foi mais acentuado nos animais de até os 18 meses de idade, $(G 1=13,0 \pm 1,7$ vs $\mathrm{G} 2=8,5 \pm 2,4$, teste $F, P<0,001)$ indican- do que até esta idade, ocorreram as maiores transformações na biometria testicular dos touros jovens. Observouse que, à medida que os animais aproximam-se da maturidade, 0 crescimento gonadal tende proporcionalmente ser menos intenso.

$\mathrm{Na}$ Tabela 2 são apresentadas as características de idade, peso e circunferência escrotal dos animais experimentais e na Tabela 3 observamse os dados da concentração, vigor e motilidade espermáticas durante 0 período estudado.

Tabela 2 - Peso vivo e circunferência escrotal (CE) em bovinos da raça Nelore $(n=20)$ durante o período experimental. 2007/2008

\begin{tabular}{lcc} 
Grupo & $\begin{array}{c}\text { Peso }(\mathrm{kg}) \\
(\mathrm{x} \pm \mathrm{s})\end{array}$ & $\begin{array}{c}\mathrm{CE}(\mathrm{cm}) \\
(\mathrm{x} \pm \mathrm{s})\end{array}$ \\
\hline $\mathrm{G} 1$ & $303,6 \pm 1,5$ & $23,8 \pm 0,8^{\mathrm{a}}$ \\
$\mathrm{G} 2$ & $428,6 \pm 1,7$ & $31,8 \pm 0,4^{\mathrm{b}}$ \\
\hline $\begin{array}{l}\text { G1 }=\text { idade entre } \\
\text { meses } \\
\text { Letras diferentes na mesma coluna indicam valores diferentes } \\
(\mathrm{P}<0,05)\end{array}$
\end{tabular}
$(P<0,05)$

\section{DISCUSSÃO}

Segundo Hahn et al. (1969) touros com baixo potencial de desenvolvimento testicular, podem ser detectados precocemente, mediante o controle de mensurações da circunferência escrotal (CE). Afirmações de Silva et al. (2002) dão conta de que as dimensões da CE em touros jovens com até 18 meses de idade, constituem um dos importantes critérios para a seleção de reprodutores, podendo ser indicativo da qualidade do sêmen, representada pela motilidade progressiva dos espermatozóides. 
Tabela 3 - Valores da concentração, vigor e motilidade espermáticas de bovinos da raça Nelore $(n=20)$ em três momentos, com intervalos de 5 meses (2007/2008)

\begin{tabular}{|c|c|c|c|c|c|c|}
\hline \multirow[t]{2}{*}{ Momento } & \multicolumn{2}{|c|}{$\begin{array}{c}\text { Concentração Espermática } \\
\left(\times 10^{6} / \mathrm{mm}^{3}\right)(\mathrm{x} \pm \mathrm{s})\end{array}$} & \multicolumn{2}{|c|}{$\begin{array}{l}\text { Vigor } \\
(0-5)\end{array}$} & \multicolumn{2}{|c|}{$\begin{array}{l}\text { Motilidade } \\
\text { (\%) }\end{array}$} \\
\hline & $\mathrm{G} 1$ & G2 & G1 & G2 & G1 & G2 \\
\hline M1 & $0,62 \pm 0,15^{a}$ & $0,81 \pm 0,13^{b}$ & $3,8 \pm 0,7$ & $3,7 \pm 0,6$ & $71 \pm 9,4$ & $65 \pm 10,2$ \\
\hline M2 & $0,7 \pm 0,17^{\mathrm{a}}$ & $0,85 \pm 0,15^{b}$ & $3,6 \pm 0,4$ & $4 \pm 0,6$ & $73 \pm 9,0$ & $81 \pm 5,3$ \\
\hline M3 & $0,88 \pm 0,10^{a}$ & $0,92 \pm 0,10^{\mathrm{b}}$ & $2,9 \pm 0,9$ & $2,8 \pm 0,6$ & $78 \pm 6,0$ & $78 \pm 8,7$ \\
\hline
\end{tabular}

$\mathrm{M} 1=\mathrm{set} / 2007 \mathrm{M} 2=\mathrm{fev} / 2008 \mathrm{M} 3=\mathrm{ju} / / 2008$

$\mathrm{G} 1=$ idade entre 10-18 meses; $\mathrm{G} 2=$ idade entre 18,1 e 24 meses

Letras diferentes na mesma coluna e na mesma linha indicam valores diferentes $(P<0,001)$.

No presente experimento, tomando-se o crescimento da CE como um dos critérios de avaliação da maturidade sexual, e comparando-se os animais com idades inferiores e superiores a 18 meses, observou-se o desenvolvimento testicular maior $(P<0,05)$ nos animais da primeira faixa etária (G1) (Tabela 1 e 2), isto é, os animais com até 18 meses de idade (G1), tiveram maior velocidade de crescimento testicular do que os animais do G2. Esse maior desenvolvimento testicular no G1 constitui ótimo parâmetro indicativo de inicio da puberdade, muito embora Dode et al. (1989), afirmem que as primeiras manifestações de puberdade são verificadas no $21^{\circ}$ mês em animais da raça Nelore, um pouco além dos parâmetros do presente experimento. Forni e Albuquerque (2004) observaram que o crescimento testicular é lento até os 10 meses de idade, e que a fase de maior desenvolvimento testicular ocorre entre 10 e 16 meses de idade, podendo ser observada nesse período uma tendência de crescimento linear, corroborando os dados obtidos na presente investigação. Segundo relatos de Sesana et al. (2007), a seleção individual para características reprodutivas por meio da CE, acelera 0 desenvolvimento do rebanho, uma vez que existe grande variabilidade genética para essa característica. Neste contexto através dos anos, incessantemente houve entre os estudiosos da andrologia animal, forte preocupação em determinar o perímetro escrotal ideal para cada fase de crescimento animal e em que período de desenvolvimento poder-se-ia executar a seleção mediante esta característica. As medidas da CE são capazes de elucidar as estimativas da precocidade sexual do animal, uma vez que a idade à puberdade varia menos em função dela própria, do que em função do peso, além de uma correlação com a precocidade sexual das irmãs e das filhas. Pereira et al. (2000), relatam que as correlações genéticas favoráveis entre a CE aos 20 meses de idade e as características reprodutivas das fêmeas, à exceção do intervalo entre partos (IP), permitem a utilização do perímetro escrotal como um dos importantes critérios de seleção para melhorar a eficiência reprodutiva dos machos (Valentim et al., 2002). Dados da tabela 2 mostram diferença significativa no tocante à $C E$ entre os grupos, não ocorrendo porem no peso, discordando em parte com Vale Filho et al. (2001), os quais observaram que o peso, bem como a consistência dos testículos, aumentam progressivamente com o avanço da idade. A relação entre o perímetro escrotal e a produção espermática encontra-se definida em Bos indicus. Segundo Moraes et al. (1998) esta peculiaridade deve ser considerada ao se utilizar o exame andrológico como instrumento para 0 aumento da fertilidade e da produtividade dos sistemas produtivos de bovinos de corte. Pinho et al. (2001) avaliaram 95 touros da raça Nelore com 18 meses de idade, mensurando a CE, 
o comprimento e o diâmetro testicular, verificando a média de $27,9 \mathrm{~cm}$, concluindo que os animais com maior CE demonstravam melhor densidade seminal, sinalizando elevada correlação entre a CE e a concentração espermática. Dados da CE do presente experimento, corroboram as afirmações de Pinho et al.(2001).

Dados relativos à concentração espermática demonstraram diferenças entre a concentração espermática $(P<0,001)$ (Tabela 3$)$, entre os grupos. Com isto, confirma-se que a seleção de touros com testículos maiores, além de tornar-se viável na prática, devido ao elevado grau de herdabilidade, sinaliza maior capacidade de produção de gametas, corroborando afirmações de Almquist e Amann (1962) e Amann (1962). Na medida em que a idade aumenta, as características físicas e morfológicas do sêmen tendem a melhorar, até atingir a maturidade sexual, quando o animal está em sua plenitude reprodutiva (Pineda et al., 2000). Ao se comparar as características biológicas do sêmen, tais como vigor e motilidade espermática, estas mantiveram-se de acordo com as recomendações do Colégio Brasileiro de Reprodução Animal (Manual,1998).

\section{CONCLUSÃO}

A maior velocidade do desenvolvimento testicular ocorreu nos animais com idade entre 10 e 18 meses, refletindo a influência da idade e do desenvolvimento corporal sobre as características reprodutivas pesquisadas. O aumento da circunferência escrotal foi acompanhado pelo aumento da concentração espermática.

\section{REFERÊNCIAS}

ALMQUIST, J.O.; AMANN, R.P. Effect of a high ejaculation frequency on sperm characteristics of Holstein bulls from puberty to two years of age.
Journal of Dairy Science, v.45, p.688-689, 1962.

AMANN, R.P. Reproductive capacity of dairy bulls. IV. Spermatogenesis and testicular germ cell degeneration. American Journal of Anatomy, v.110, p.69-78, 1962.

BERGMANN, J.A.G.; QUIRINO, C.R.; VALE FILHO, V.R.et al. Evalution of four mathematical functions to describe scrotal circunference maturation in Nelore bulls. In: World Congress on Genetics Applied To Livestock Production Armidale, v.27, p. 67-70, 1998.

Colégio Brasileiro de Reprodução Animal (CBRA). MANUAL PARA EXAME ANDROLÓGICO E AVALIAÇÃO DE SÊMEN ANIMAL, 2.ed., Belo Horizonte, 1998. 230p.

DIAS, J.C.; ANDRADE, V.J.; MARTINS, J.A.M. et al. Correlações genéticas e fenotípicas entre características reprodutivas e produtivas de touros da raça Nelore. Pesquisa Agropecuária Brasileira, v.43, n.1, p. 53-59. 2008.

DODE, M.A.N.; SCHENK, J.A.P.; SILVA, A.E.D.F. Determinação da puberdade em machos nelore e mestiços. Revista Brasileira de Reprodução Animal, v.1, p. 18,1989.

FRENEAU, G.E.; VALE FILHO, V.R.; MARQUES JR, A.P.et al. Puberdade em touros Nelore criados em pasto no Brasil:

características corporais, testiculares e seminais e de índice de capacidade andrológica por pontos. Arquivo Brasileiro de Medicina Veterinária e Zootecnia, v.58, n.6, p.11071115, 2006.

FORNI, S.; ALBUQUERQUE, L.G. Avaliação de características biométricas de testículos de bovinos Nelore. In: Simpósio da Sociedade Brasileira de Melhoramento Animal, 5., 2004. Anais... Pirassununga, 2004. p.110-121.

HAHN, J.; FOOTE, R.H.; SEIDEL, G.E.

Testicular growth and related sperm output in dairy bulls. Journal of Animal Science, v. 29, n.1, p.41-47, 1969.

MORAES, J.C.F.; HORN, M.M.; ROSADO JR, A.G. Exame andrológico em touros: qualidade dos indicadores da aptidão reprodutiva em distintos grupos raciais. Revista Ciência Rural, v.28, n.4, p. 647-652, 1998.

PACHECO, A.; QUIRINO, C.R.; SILVA, J.F.S.et al. Efeito da idade e de fazenda sobre as características seminais e perímetro escrotal em touros da raça Guezerá criados no norte e noroeste do Rio de Janeiro/Brasil. Archivos Latino Americanos de Producción Animal, v.15, n.4, p.157-164, 2007 
PEREIRA, E.; ELER, J.E.; FERRAZ J.B.S. Correlação Genética entre perímetro escrotal e algumas características reprodutivas na raça Nelore. Revista Brasileira de Zootecnia, v.29, n.6, p. 1676-1683, 2000.

PINEDA, N.R.; FONSECA, V.O.; ALBUQUERQUE, L.G. Estudo preliminar da influência do perímetro escrotal sobre a libido em touros jovens da raça Nelore. Arquivo Brasileiro de Medicina Veterinária e Zootecnia, v.52, n.1, p.7-16, 2000.

PINHO, T.G.; NOGUEIRA, L.A.G.; PINTO, P.A. et al. Características seminais de touros jovens nelore (Bos taurus indicus) de acordo com a biometria e morfologia testicular. Revista Brasileira de Reprodução Animal, v.25, n.2, p.187-189, 2001.

SESANA, R.B.; ALBUQUERQUE, L.G.; SILVA, J.A.L.V. et al. Estimativas de herdabilidade e correlação genética de perímetro escrotal, medido em diferentes idades, em animais Nelore. In: REUNIÃO ANUAL DA SOCIEDADE BRASILEIRA DE ZOOTECNIA, 44., 2007. Anais... Jaboticabal, 2007. p.1-5, 2007.

SILVA, A.E.D.F.; UNANIAN, M.M.; CORDEIRO, C.M.T. Relação da circunferência escrotal e parâmetros da qualidade do sêmen em touros da raça Nelore, PO. Revista Brasileira de Zootecnia, v.31, n.3, p.1157-1165. 2002.

SILVEIRA, J.C.; CONCEPTA, M.; MASCIOLI, A.S. et AL.n Fatores ambientais e parâmetros genéticos para características produtivas e reprodutivas em um rebanho Nelore no estado do mato grosso do sul. Revista Brasileira de Zootecnia, v.33, n.6, p.1432-1444, 2004.
UNANIAN, M.; SILVA, A.E.D.F. Estudo da precocidade sexual em bovinos machos da raça Nelore. In: O MELHORAMENTO DO NELORE A CAMPO: Fazenda Novo Mundo (Grupo Manah), 1997. Anais... [s.I.]: Manah, 1997. p.68.

UNANIAN, M.M.; FELICIANO SILVA, A.E.D.; McMANUS, $C$. et al. Características biométricas testiculares para avaliação de touros zebuínos da raça Nelore. Revista Brasileira de Zootecnia, v.29, n.1, p.136-144, 2000.

VALE FILHO, V.R.; ANDRADE, V.J.; QUIRINO, C.R. et al. Perfil andrológico de touros da raça Tabapuã (Bos taurus indicus) de um a dois anos de idade, criados extensivamente nos estados de Minas Gerais, Bahia e Espírito Santo, Brasil. Revista Brasileira de Reprodução Animal, v.25, n.2, p.189-192, 2001.

VALENTIM, R.; ARRUDA, R.P.; BARNABE, R.C. et al. Biometria testicular de touros Nelore (Bos taurus indicus) e touros cruzados Nelore europeu (Bos taurus indicus $\times$ Bos taurus taurus) aos 20 e 24 meses de idade. Brazilian Journal Veterinary Medicine and Animal Science, v.39, n.3, p.113-120, 2002. 